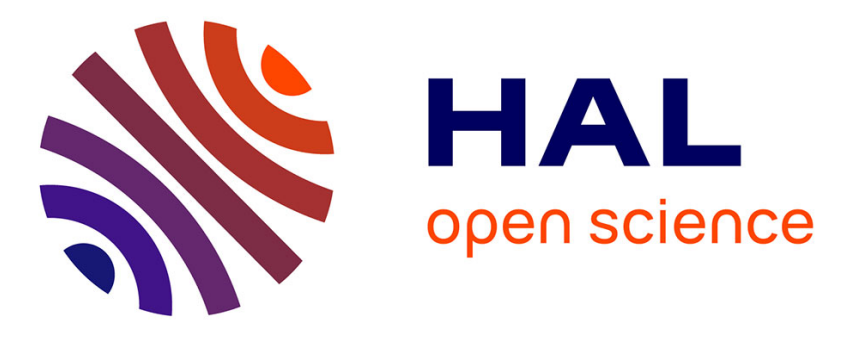

\title{
Sulfuric Acid Influence on the Nitrocompounds Detonation Reactions
}

\author{
V. Gamezo, S. Khoroshev, B. Kondrikov, G. Kozak
}

\section{To cite this version:}

V. Gamezo, S. Khoroshev, B. Kondrikov, G. Kozak. Sulfuric Acid Influence on the Nitrocompounds Detonation Reactions. Journal de Physique IV Proceedings, 1995, 05 (C4), pp.C4-395-C4-405. 10.1051/jp4:1995432 . jpa-00253737

\section{HAL Id: jpa-00253737 https://hal.science/jpa-00253737}

Submitted on 1 Jan 1995

HAL is a multi-disciplinary open access archive for the deposit and dissemination of scientific research documents, whether they are published or not. The documents may come from teaching and research institutions in France or abroad, or from public or private research centers.
L'archive ouverte pluridisciplinaire HAL, est destinée au dépôt et à la diffusion de documents scientifiques de niveau recherche, publiés ou non, émanant des établissements d'enseignement et de recherche français ou étrangers, des laboratoires publics ou privés. 


\title{
Sulfuric Acid Influence on the Nitrocompounds Detonation Reactions
}

\author{
V.N. Gamezo, S.M. Khoroshev, B.N. Kondrikov and G.D. Kozak \\ Mendeleev University of Chemical Technology, 9 Miusskaja Sq., 125047 Moscow, Russia
}

\begin{abstract}
The detonation failure diameter $d_{f}$ and detonation velocity $D$ of mixtures of nitromethane, trinitrotoluene, dinitrotoluene, and trinitrobenzene with sulfuric acid and oleum have been measured in the wide range of concentrations. It was shown that the detonation ability of the nitrocompounds depends significantly on the sulfuric acid content. The minimum value of $\mathrm{d}_{\mathrm{f}}$ for the mixture TNT/oleum is about $2 \mathrm{~mm}$, i.e., 30 times less, than that for pure melted TNT, and practically equal to $d_{f}$ of nitroglycerine. In some cases, the temperature dependencies of failure diameter have been determined. Dremin theory of detonation failure diameter was used to treat quantitatively the results of experiments with the NM and TNT solutions in the frameworks of the Arrhenius chemical kinetics.
\end{abstract}

\section{INTRODUCTION}

The strong sensibilizing effect of small quantity of the inorganic acids on the nitrocompounds detonation was observed earlier [1]. Nitromethane was used as a model. There was shown that the nitromethane detonation is greatly influenced by small concentration of additives. Of course it would be interesting to find out how it is affected by the large ones.

In this paper the sulfuric acid influence on the detonation ability of mixtures of sulfuric acid or oleum with nitromethane (NM), trinitrotoluene(TNT), dinitrotoluene(DNT), and trinitrobenzene(TNB) was studied in a wide range of the components concentrations ${ }^{1}$ (from 93 to $108 \% \mathrm{H}_{2} \mathrm{SO}_{4}$ in the concentrated sulfuric acid and oleum, and up to $64 \%$ of the acid in the mixture with nitrocompound). Dremin theory of detonation failure diameter [2-4] was used to treat quantitatively the results of experiments with NM and TNT solutions.

The work was mainly implemented during 1986-1990 as a constituent part of investigations were to reveal and to remove causes of accidents being arisen under the TNT production on the third stage of DNT to TNT nitration.

${ }^{1}$ Concentration of oleum and acid is expressed by percentage of sulfuric acid S. Content of suitable sulfuric ingredient in mixture with explosive is denioted by $\mathrm{C}_{\mathrm{S}}$. 


\section{EXPERIMENTAL}

The experiments were carried out using the commercial grade TNT (solidification temperature, S.T. $=80.2^{\circ} \mathrm{C}$ ) and $2,4-\mathrm{DNT}\left(\mathrm{S} . \mathrm{T} .=68.9-69.2^{\circ} \mathrm{C}\right)$. TNB was produced in the laboratory and purified by recrystallyzation from nitric acid (S.T. of TNB recrystallyzed was $122.8^{\circ} \mathrm{C}$ ). The commercial-grade NM was distilled at atmospheric pressure over $\mathrm{P}_{2} \mathrm{O}_{5}$. The main fraction $100.7-101.3^{\circ} \mathrm{C}$ was taken for the experiments. The detonation failure diameter of this fraction of NM measured repeatedly every $1-2$ months during about two years was $13 \pm 0.5 \mathrm{~mm}$. The commercial-grade sulfuric acid ( $94 \%$ concentration) and oleum containing $60 \%$ "free" sulfuric anhydride were used to prepare the solutions containing up to $108.2 \% \mathrm{H}_{2} \mathrm{SO}_{4}$. The $\mathrm{H}_{2} \mathrm{SO}_{4}$ concentration was determined by titration.

The detonation failure diameter $d_{f}$ was measured in glass tubes (the wall thickness is $\sim 1.5 \mathrm{~mm}$ ) by the method go-no-go. Dark, open, and half-dark points (Fig. $1,3,5$ ) correspondingly designate detonation, failure of detonation immediately after initiation, and detonation extinguishment after more or less prolonged (up to several $\mathrm{d}$ in length) path of the detonation process. The tubes had the smooth widening in the upper part for initiator or booster setting, and for the continuous transition to the steady-state detonation. A pellet of pressed phlegmatized RDX $\left(\mathrm{d}=12 \mathrm{~mm}, \mathrm{~m}=2 \mathrm{~g}, \rho=1.66 \mathrm{~g} / \mathrm{cm}^{3}\right)$ used as the booster was protected by the thin film of fluoropolymer to avoid the strong acid action on the booster. The result of the experiment was determined by means of the metal witness-plate attached directly to the tube wall.

The experiments at high temperature were carried out in the glass tubes inserted in tubes of higher diameter and isolated by the layer of cotton wool placed between the tubes walls. The assembly was heated to temperature $5^{\circ} \mathrm{C}$ higher the proposed experiment temperature. After that the liquid investigated heated to the same temperature was quickly poured into the central glass tube, all the setting was placed into the explosion chamber, and after some delay monitored by means of the preliminary estimated cooling curve the detonation was initiated.

The detonation velocity $D$ was measured in the steel tubes $(\mathrm{d}=10 \mathrm{~mm}, \delta=13 \mathrm{~mm}, l=180-250 \mathrm{~mm})$. The detonation process luminosity was registred by the Russian streak camera SFR-2 through the radial holes $(\mathrm{d}=1.5-2.0 \mathrm{~mm})$, drilled in the wall of the tube at distance of $15 \mathrm{~mm}$ one from another. The holes as well as the bottom of the tube were closed by the glass plates, adhered by the acid persistent glue.

The measurements were made mainly under the initial temperature $\mathrm{T}_{n}=18.5^{\circ} \mathrm{C}$ for $\mathrm{NM}$ solutions, $85-86^{\circ} \mathrm{C}$ for TNT and DNT solutions, and $110^{\circ} \mathrm{C}$ for TNB solutions (except the cases where the effect of initial temperature was estimated)

\section{RESULTS}

NM: The results of experiments with the solutions of $\mathrm{NM}^{\text {in }} \mathrm{H}_{2} \mathrm{SO}_{4}$ concentration of $93 \%$ and $100.5 \%$ are represented in Figs. 1 and 2. The sulfuric acid addition leads to the failure diameter quick decrease, after that the flat minimum (about $1.5 \mathrm{~mm}$ ) is reached, and progressive grow of the $d_{f}$ value follows. The detonation velocity at $\mathrm{C}_{S} \leq 20 \%(S=100.5 \%)$ is practically constant, and equal to that of the neat NM $\left(6.34 \mathrm{~mm} / \mu\right.$ s at $\left.\mathrm{T}=18.5^{\circ} \mathrm{C}\right)$. For $\mathrm{S}=93 \%$ the $\mathrm{D}\left(\mathrm{C}_{S}\right)$ dependence was not measured.

TNT: Oleum of concentration $100.6,101.7,103.8$ and $108.2 \% \mathrm{H}_{2} \mathrm{SO}_{4}$ was used to obtain TNT solutions. The results of the measurements of failure diameter of the solutions are represented in the Figures 3 and 4 . Curves received at different oleum concentrations are similar to each other: as the oleum content $\mathrm{C}_{S}$ in mixture increases, detonation failure diameter reduces down to the minimum value and then rises. Minimum critical diameter $\mathrm{d}_{\mathrm{f}}^{\min }(\mathrm{mm})$ depends on $\mathrm{S}$ :

$$
\log _{10} d_{f}^{\min }=1.2 \cdot 10^{7} \cdot \exp (-0.1619 \cdot S)
$$


The content of oleum in the mixture corresponding to the minimum of the curve is about $40-50 \%$ and tends to rise in these limits, when $S$ grows. The minimum value of $d_{f}$ for TNT diluted by oleum, $\mathrm{S}=108.2 \%$, is about $2 \mathrm{~mm}$, i.e. 30 times less, than that for pure melted TNT. It is practically equal to the detonation failure diameter of nitroglycerine.

The influence of oleum content on detonation velocity of TNT is shown in Fig.2. The velocity of detonation is almost constant up to $\mathrm{C}_{\mathrm{S}}=50 \%$. Further growth of oleum content results in the considerable decrease of the $\mathrm{D}$ value leading to extinguishment of detonation.

Influence of nitric acid on detonation of TNT solutions in oleum is of the obvious practical interest. Solubility of nitrocompounds in the sulfuric-nitric acids mixture is far less, than in oleum or sulfuric acid alone. One can introduce without loss of solubility to the mixture containing 40/60 TNT/oleum $(\mathrm{S}=103.8 \%)$ no more than $4 \%$ of nitric acid. Experiments carried out with such solution at concentration of nitric acid 2.5 and $4 \%$, show that, regardless of wide-spread opinion, $\mathrm{d}_{\mathrm{f}}$ of TNT solution in oleum does not grow. It remains constant and equal to 11-12 mm. Introducing of extra quantity of nitric acid results in emulsion formation, and experiments in this concentration region were not carried out.

DNT: The detonation failure diameter of pure melted DNT up to now is not estimated. Using some approximation, we can appraise it at $80-90^{\circ} \mathrm{C}$ as about $0.5 \mathrm{~m}$. In the steel tubes $(\mathrm{d}=10 \mathrm{~mm}, \delta=13 \mathrm{~mm})$ the detonation extinguished even at $190^{\circ} \mathrm{C}$. However, the steady-state detonation of the DNT solutions in oleum at $\mathrm{S}=103.8 \%, \mathrm{C}_{\mathrm{S}}=50 \%$ and $60 \%\left(\mathrm{~T}_{0}=85^{\circ} \mathrm{C}\right)$ was observed. The mean detonation velocity of the solutions was equal to $5.5 \mathrm{~mm} / \mu \mathrm{s}$ (Fig.2). At $\mathrm{C}_{\mathrm{S}}=40 \%$ the detonation of the solution after considerable $(110-130 \mathrm{~mm})$ propagation failed, at $\mathrm{C}_{\mathrm{S}}=70 \%$ the detonation was not observed. It is quite obviously that oleum reacts with DNT sensibilizing its detonation.

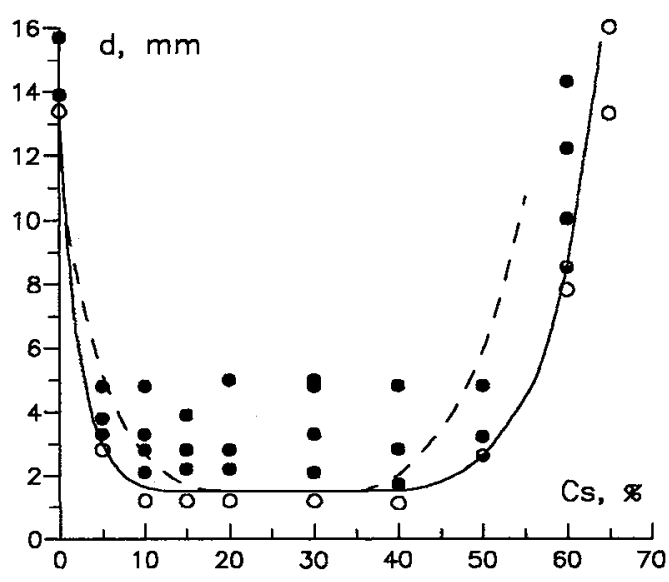

Fig.1. Influence of sulfuric acid on detonation failure diameter of NM. Dark, open, and halfdark points correspondingly designate detonation, failure of detonation, and detonation extinguishment. The points and the solid line (which separates the detonation region from the region of detonation failure) represent the results for $S=100.5 \%$. The dashed line corresponds to $\mathrm{S}=93 \%$.

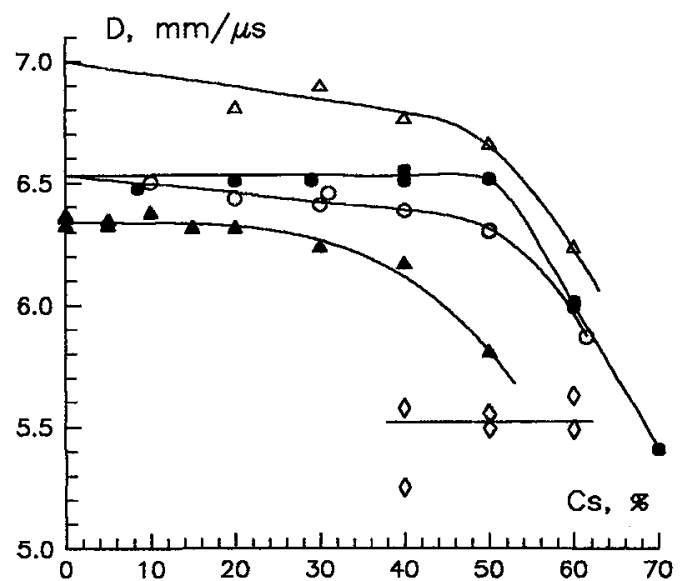

Fig.2. The results of detonation velocity measurements of the mixtures of nitrocompounds and oleum:
$\Delta$ - TNB/oleum $\left(\mathrm{S}=103.5 \%, \mathrm{~T}_{0}=110^{\circ} \mathrm{C}\right)$,
- TNT/oleum $\left(\mathrm{S}=103.8 \%, \mathrm{~T}_{0}=85-86^{\circ} \mathrm{C}\right)$,
O - TNT/oleum $\left(\mathrm{S}=101.6 \%, \mathrm{~T}_{0}=85-86^{\circ} \mathrm{C}\right)$,
○ - DNT/oleum $\left(\mathrm{S}=103.8 \%, \mathrm{~T}_{0}=85^{\circ} \mathrm{C}\right)$,
$\Delta$ - NM/oleum $\left(\mathrm{S}=100.5 \%, \mathrm{~T}_{0}=18.5^{\circ} \mathrm{C}\right)$. 

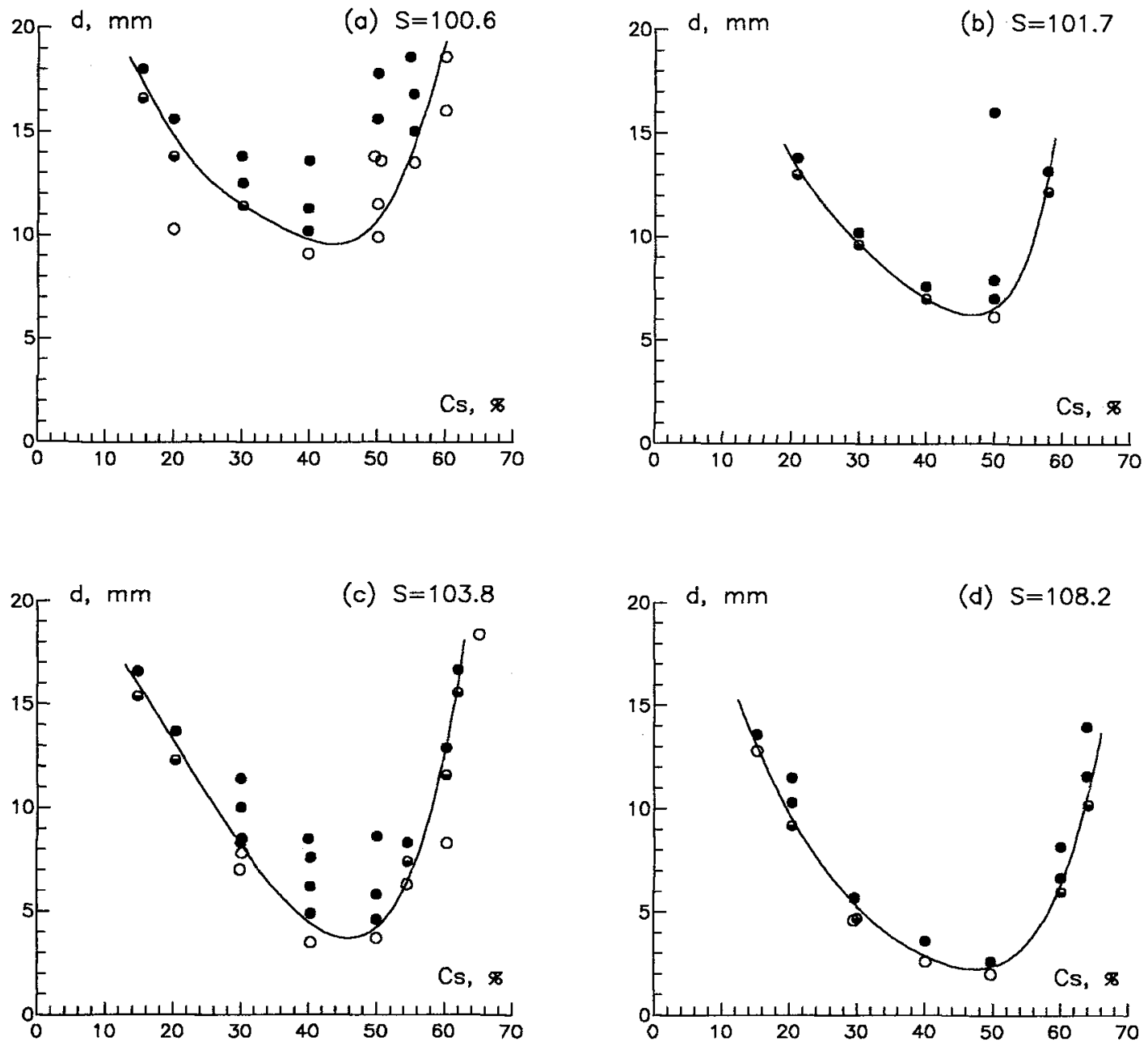

Fig.3. The results of detonation failure diameter measurements in the $T N T /$ oleum mixtures, $\mathrm{T}_{0}=85-86^{\circ} \mathrm{C}$. Dark, open, and half-dark points correspondingly designate detonation, failure of detonation, and detonation extinguishment. The curve separates the detonation region from the region of detonation failure. 


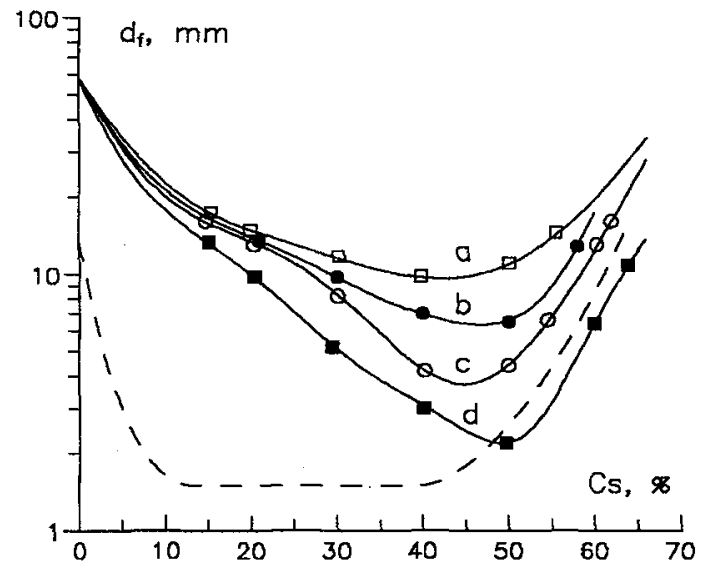

Fig.4. The detonation failure diameter of the mixtures of TNT (a-d) and NM (dashed line) with oleum versus its content in the solution. Oleum concentration S, $\%$ : a - $100.6 \%, b$ $101.7 \%, c-103.8 \%, d-108.2 \%$, and $100.5 \%$ for the mixtures of NM. The points are the mean experimental values; the solid lines are calculated for TNT mixtures using the kinetic scheme suggested

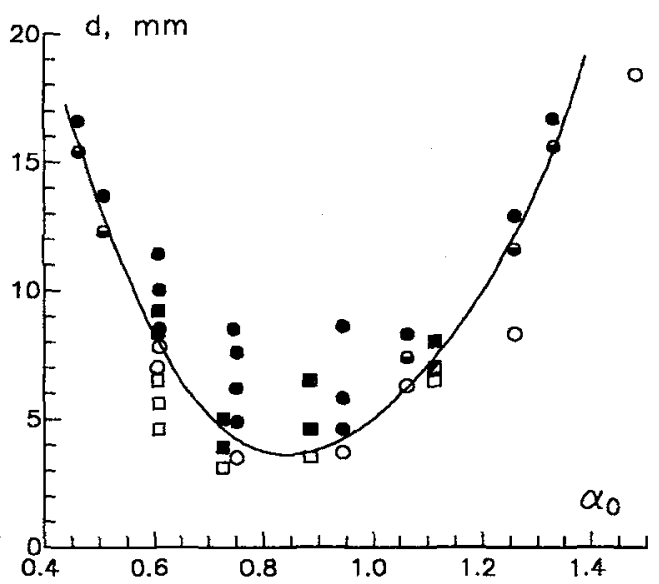

Fig.5. The detonation failure diameter versus inverse equivalent ratio $\alpha_{0}$ for TNT/oleum $\left(\mathrm{S}=103.8 \%, \mathrm{~T}_{0}=85^{\circ} \mathrm{C}\right.$, circles) and $\mathrm{TNB} /$ oleum ( $\mathrm{S}=103.5 \%, \mathrm{~T}_{0}=110^{\circ} \mathrm{C}$, quadrangles) mixtures. Dark, open, and half-dark points correspondingly designate detonation, failure of detonation, and detonation extinguishment. The curve is common for two mixtures, and separates the detonation region from the region of detonation failure.

TNB: The experiments with TNB solutions were carried out at the oleum concentration $S=103.5 \%$. At $110^{\circ} \mathrm{C}$ one can get the solutions, containing up to $80 \%$ of TNB. The results of the detonation velocity measurements and the detonation failure diameter of the TNB solutions in oleum estimations are shown in Figs. 2 and 5. Comparing these data with the results observed for TNT in oleum solutions $(S=103.8 \%$, Fig.3), one can conclude, that the curves are not only similar to each other, but even the values of $d_{f}^{\text {min }}$ for TNT and TNB are almost exactly the same. However, to reach the same $d_{f}$ values in case of TNB the higher temperature is required. In coordinates of $d_{f}$ versus $1 / \alpha_{0}$ the data for TNT and TNB coincide with each other (Fig.5).Here $\alpha_{0}$ is the equivalent ratio of the mixture

$$
\alpha_{0}=(\mathrm{O}) /[2(\mathrm{C})+(\mathrm{H}) / 2-(\mathrm{S})]
$$

where $(\mathrm{O}),(\mathrm{C}),(\mathrm{H})$, and $(\mathrm{S})$ are the molecular fractions of the elements in the mixture.

Effect of initial temperature: The $\mathrm{d}_{\mathrm{f}}\left(\mathrm{T}_{0}\right)$ dependencies were determined for $50 / 50$ mixtures of $\mathrm{H}_{2} \mathrm{SO}_{4}$ with NM (at $\mathrm{S}=93.0 \%$ ), TNT (at $\mathrm{S}=103.0 \%$ ), and TNB ( $\mathrm{S}=103.5 \%$ ). As for number of other explosives, the straight lines $\log _{10} d_{f}=A+B / T_{0}$ were obtained. Constants $A$ and $B$ together with the data [5] for neat TNT and NM are represented in the Table 1 
Table 1. The constants $A$ and $B$ of the straight lines $\log _{10} d_{f}=A+B / T_{0}$.

\begin{tabular}{||lrrrr||}
\hline Explosive & $\mathrm{T}_{0}, \mathrm{~K}$ & $\mathrm{~A}$ & $\mathrm{~B}$ & $\begin{array}{r}\mathrm{d}_{\mathrm{f}}(353 \mathrm{~K}), \mathrm{mm} \\
\text { (calculation) }\end{array}$ \\
\hline & & & & \\
TNT/oleum $50 / 50(\mathrm{~S}=103.0 \%)$ & $336-370$ & -2.176 & 1041 & 5.9 \\
TNB/oleum $50 / 50(\mathrm{~S}=103.5 \%)$ & $358-383$ & -0.898 & 675 & 10.3 \\
$\mathrm{NM} / \mathrm{H}_{2} \mathrm{SO}_{4} 50 / 50(\mathrm{~S}=93.0 \%)$ & $253-338$ & -1.194 & 585 & 2.9 \\
$\mathrm{TNT}$ & $357-513$ & -1.667 & 1231 & 66.1 \\
$\mathrm{NM}$ & $273-358$ & -0.866 & 581 & 6.0 \\
\hline
\end{tabular}

\section{DISCUSSION}

The quantitative treatment of results in this paper is represented only for mixtures on base of NM and TNT, because the information on $d_{f}$ dependencies for DNT and TNB mixtures is not sufficient for calculation. Dremin theory of detonation failure diameter [2-4] was used to treat the results. According to this theory based on conception of pulsating reaction zone we can calculate the adiabatic induction period $\tau_{3}$ in this zone near the limit of detonation propagation at temperature of shock-compressed substance $T_{3}$. The calculation procedure in all details is given in [6]. The same velocity of the reaction failure wave $v=3.8 \mathrm{~mm} / \mu$ s for all the mixtures of $\mathrm{NM}$ as well as for neat NM [7] was accepted. Similarly, the value $v=2.76 \mathrm{~mm} / \mu \mathrm{s}$, reported in [3] for liquid TNT, was used for all TNT mixtures. The generalized Hugoniot of liquids $\mathbf{D}=\mathbf{C}_{0}+0.29+1.63 u$ [8] was used for oleum. The sound velocity $\mathbf{C}_{0}$ was determined in paper [9]. The Hugoniot adiabat of the mixture was defined supposing the components specific volume additivity.

\subsection{NM solutions.}

The polytropic exponent of detonation products $\gamma$ for the NM solutions is assumed to be the same function of initial density $\rho_{0}$ as for pure nitromethane [7]: $\gamma=\left(0.656 / \rho_{0}\right)+0.703+1.105 \rho_{0}\left(\rho_{0}\right.$ in $\left.\mathrm{g} / \mathrm{cm}^{3}\right)$. The shock temperature of the solutions was calculated by the method [8]. These data were used to calculate the temperature $T_{3}$, and the corresponding ignition delays $\tau_{3}$ along the solid curve on Fig. 1 .

The decomposition rate constant of pure nitromethane [5] is

$$
\mathrm{k}_{\mathrm{l}}=\mathrm{k}_{01} \exp \left(-\mathrm{E}_{1} / \mathrm{RT}\right)
$$

where $\mathrm{k}_{01}=8 \cdot 10^{14} \mathrm{~s}^{-1}, \mathrm{E}_{\mathrm{l}}=210 \mathrm{~kJ} / \mathrm{mol}$. The activation energy is close to the values reported in [4], and obtained for thermal decomposition of NM at pressure of order of $10^{4}-10^{5} \mathrm{~Pa}$ (see compilation [10]).

The decomposition rate on addition of sulfuric acid increases, obviously due to $\mathrm{CH}_{3} \mathrm{NO}_{2}-\mathrm{H}_{2} \mathrm{SO}_{4}$ interaction. It is known [11], that this interaction gives $\mathrm{CH}_{3} \mathrm{NO}_{2} \mathrm{H}^{+}$ion, which is allowed to be named the nitromethonium ion by analogy with $\mathrm{H}_{2} \mathrm{O} \cdot \mathrm{H}^{+}$hydroxonium ion. The possible complexes of this ion with sulfuric acid are the nitromethonium bisulfate $\mathrm{CH}_{3} \mathrm{NO}_{2} \mathrm{H}^{+} \cdot \mathrm{HSO}_{4}^{-}$, and the nitromethonium sulfate $\left[\mathrm{CH}_{3} \mathrm{NO}_{2} \mathrm{H}^{+}\right]_{2} \cdot \mathrm{SO}_{4}{ }^{2-}$. Our analysis shows that the sulfate ion formation is more essential source of the detonation reaction acceleration. When sulfuric acid content in the mixture is large enough (more than 30$35 \%$ ), one can suppose that this complex is formed quantitatively, and nitromethane in the shock wave reacts quickly with sulfuric acid according to reaction

$$
2 \mathrm{CH}_{3} \mathrm{NO}_{2}+\mathrm{H}_{2} \mathrm{SO}_{4} \stackrel{\mathrm{K}_{\mathrm{C}}}{\longrightarrow}\left[\mathrm{CH}_{3} \mathrm{NO}_{2} \mathrm{H}^{+}\right]_{2} \cdot \mathrm{SO}_{4}{ }^{2-}\left(\mathrm{K}_{\mathrm{C}} \rightarrow \infty\right)
$$

The complex formed is decomposed. The decomposition rate constant supposedly is 


$$
\mathrm{k}_{2}=\mathrm{k}_{02} \exp \left(-\mathrm{E}_{2} / \mathrm{RT}\right) \text {, }
$$

and $k_{2}\left(T_{3}\right) \gg>k_{1}\left(T_{3}\right)$. Our estimation shows that $E_{2} \cong E_{1} / 2$. In this case to compute the constants ratio, one can use the expression

$$
\tau_{3} \mathrm{~N} /\left(\tau^{0}{ }_{3} \mathrm{~N}_{0}\right)=2 \mathrm{Y}[1-\mathrm{Y} \ln (1+1 / \mathrm{Y})], \quad \mathrm{Y}=\left(\mathrm{k}_{1} \mathrm{~N} / \mathrm{k}_{2} a \mathrm{C}_{2}\right)
$$

being integral of the differential equation of adiabatic self-heating for two parallel reactions of the first order at the fixed (time-independent) reagents concentrations. In Eq.(4) $\mathrm{N}_{0}$ and $\mathrm{N}$ are the initial and the current molar concentration of nitromethane, $\mathrm{C}$ is the molar concentration of the complex. For bisulfate $a=1$, for sulfate $a=2 . \tau_{3}^{0}$ is the hypothetical period of induction in the system, where the complex is not formed, nitromethane concentration remains equal to $\mathrm{N}_{0}$, and the heat release rate is not influenced by sulfuric acid:

$$
\tau_{3}^{0}=\mathrm{C}_{\mathrm{v}} \rho \mathrm{RT}_{3}{ }^{2} /\left(\mathrm{N}_{0} \mathrm{Qv}_{\mathrm{v}} \mathrm{E}_{01}\right) \cdot \exp \left(\mathrm{E}_{1} / \mathrm{RT}_{3}\right)
$$

Here $Q_{V}$ is the heat of NM decomposition, $C_{V}$ and $\rho$ are the heat capacity and density of mixture. As the sulfuric acid is added to the system $\tau_{3}^{0}$ increases rapidly. For example, $\tau_{3}^{0} \tau_{3}=570$ when $C_{S}=60 \%$.

If the proposed model is true, the straight line must be obtained in $1 / \mathrm{T}_{3}-\log _{10}\left(\mathrm{k}_{1} / \mathrm{k}_{2}\right)$ coordinates. The slope and intercept of this line give the difference of the activation energies $E_{1}-E_{2}$, and the ratio of the preexponential factors $k_{01} / k_{02}$.

By assuming that nitromethonium sulfate is formed, the experimental results allow to obtain the constants $\mathrm{k}_{02}$ and $\mathrm{E}_{2}$ directly: when $\mathrm{C}_{\mathrm{S}}>44.5 \%$ there is no free nitromethane in the system, and the self-heating equation reduces to the usual relation of the type (5) for $k(T)=k_{2}(T)$.

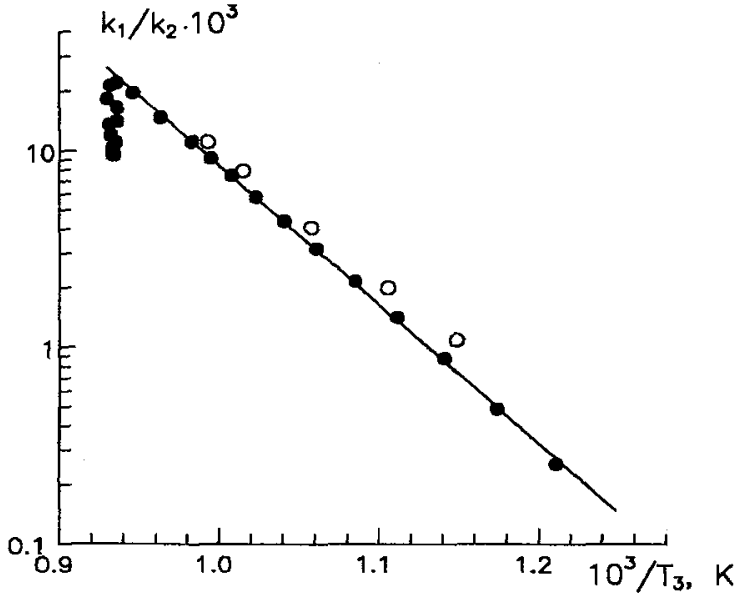

Fig.6. The $k_{1} / k_{2}$ ratio calculated by the formula (4) versus $1 / \mathrm{T}_{3}$ for mixtures $\mathrm{NM} / \mathrm{H}_{2} \mathrm{SO}_{4}$ : - on the basis of $d_{f}\left(C_{S}\right)$ for $S=100.5 \%, O$ - using $d_{f}\left(T_{0}\right)$ for $S=93 \%$.

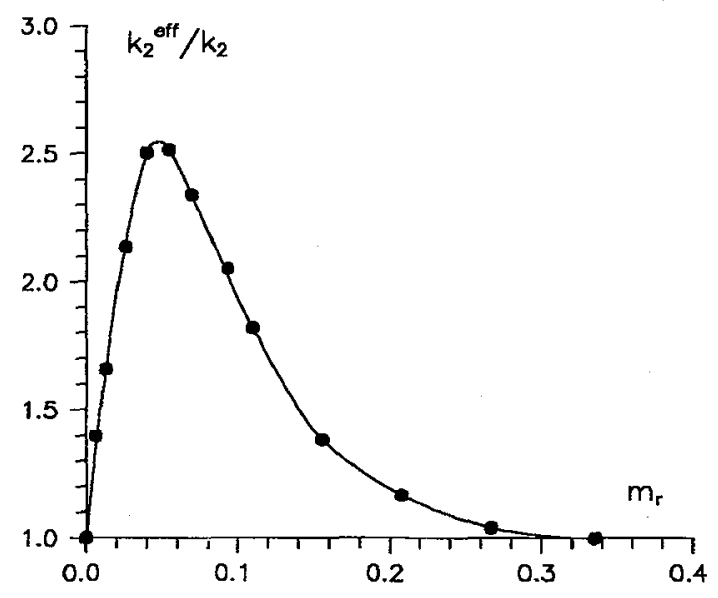

Fig.7. The ratio of the effective rate constant $\mathrm{k}_{2}$ eff given by Eq.(4), to the decomposition rate constant of the nitromethonium sulfate $k_{2}$ as a function of the molar ratio of sulfuric acid to nitromethane. 
The dependence of the $\log _{10}\left(k_{1} / k_{2}\right)$ versus $1 / T_{3}$ calculated by the formula (4) (Fig.6) gives the line $\log _{10}\left(k_{1} / k_{2}\right)=4.89-6970 / T_{3}$ obtained in the range of $30 \% \leq C_{S} \leq 64 \%$, from which $E_{2}-E_{1}=133 \mathrm{~kJ} / \mathrm{mol}$, and $\mathrm{k}_{01} / \mathrm{k}_{02}=7.7 \cdot 10^{4}$. This corresponds to $E_{2}=77 \mathrm{~kJ} / \mathrm{mol}$ for $E_{1}=210 \mathrm{~kJ} / \mathrm{mol}$. In the range of $44 \% \leq \mathrm{C}_{\mathrm{S}} \leq 64 \%$, where under the assumption $\mathrm{K}_{\mathrm{C}} \rightarrow \infty$ all nitromethane is turned to the nitromethonium sulfate, the dependence $\log _{10} \mathrm{k}_{2}\left(1 / \mathrm{T}_{3}\right)$ results in $\mathrm{E}_{2}=79 \mathrm{~kJ} / \mathrm{mol}$, and $\mathrm{k}_{02}=1.7 \cdot 10^{10} \mathrm{~s}^{-1}$.

When sulfuric acid content is less than $30 \%$ the points (Fig.6) tend to fall down, tracing out a loop with a minimum at $\mathrm{C}_{\mathrm{S}}=6-8 \%$, then tend to line again. The initial part of the dependence is demonstrated in Fig. 7 , where the relation of the effective rate constant $\mathrm{k}_{2}^{\text {eff }}$ to the value of $\mathrm{k}_{2}$, which is approximately constant in the concentration range considered, is plotted as a function of the molar ratio of sulfuric acid to nitromethane. Obviously, it does mean that the third group of reactions at low $\mathrm{H}_{2} \mathrm{SO}_{4}$ content takes place, probably connected with the aci-ion [12] formation under the acid influence. As sulfuric acid content increases, the conversion velocity of $\mathrm{NM}$ to aci-ion rises, but in the strong acid medium at high concentration of $\mathrm{H}_{2} \mathrm{SO}_{4}$, aci-form does not exist. So, for the large enough concentration of the acid the reaction reduces to the formation and decomposition of the nitromethonium sulfate, the overall decomposition rate decreases, $\mathrm{k}_{2}{ }^{\mathrm{eff}} / \mathrm{k}_{2}$ ratio tends to 1 .

Dependence $d_{f}\left(T_{0}\right)$ measured for the mixture $50 / 50$ of nitromethane and sulfuric acid $(S=93 \%)$ was also processed in framework of Dremin theory. To do this it is required to know the experimental values of detonation velocity if only at any one value of initial temperature. The effect of $T_{0}$ on $D$ was found using the coefficient of heat expansion. $T_{0}$ on $T_{3}$ influence was determined by the method proposed in [8].

The results of the calculations (for $\mathrm{D}_{298}=5.75 \mathrm{~mm} / \mu \mathrm{s}$ ) are shown in Fig.6 (open circles). The dependence $d_{f}\left(T_{0}\right)$ gives practically the same values of $k_{2}$, as the dependence $d_{f}\left(C_{S}\right)$. The variation of the initial temperature is no effect on the main result: the interaction of nitromethane with sulfuric acid leads, with the qualitative yield, to the formation of nitromethonium sulfate, the decomposition rate of which under the conditions considered is two orders of magnitude greater than that of nitromethane.

\subsection{TNT solutions}

The values of $\tau_{3}$ and $\mathrm{T}_{3}$ calculated for mixture (50/50) $\mathrm{TNT}_{2} \mathrm{H}_{2} \mathrm{SO}_{4}(\mathrm{~S}=103.0 \%)$ at different initial temperature are placed on the line:

$$
\log _{10}\left(\tau_{3} / \mathrm{T}_{3}^{2}\right)=-a+b / \mathrm{T}_{3}
$$

The values of $a$ and $b$ depend on equations of state of original components and explosion products, mainly, on polytropic exponent of detonation products $\gamma$. For mixtures of TNT and sulfuric acid this value is not determined as yet. Changing $\gamma$ in the range of 2.8-3.2, one can get the $a$ and $b$ constants to be equal to $18 \pm 1$ and $(15.7 \pm 0.5) \cdot 10^{3}$, respectively. The activation energy of the reaction is changed correspondingly in the range of $100-120 \mathrm{~kJ} / \mathrm{mol}$. The activation energy of TNT detonation reaction calculated in [4], is equal to $109 \mathrm{~kJ} / \mathrm{mol}$, i.e. it corresponds to the middle of the interval obtained here. To simplify further calculations, the suggestion is proposed that the activation energies of the reactions determining $d_{f}$ of the $\mathrm{H}_{2} \mathrm{SO}_{4}$ solutions, are equal to each other and close to the value of $109 \mathrm{~kJ} / \mathrm{mol}$.

The sequence of kinetic equations of the main reactions taken place at detonation of TNT/ $\mathrm{H}_{2} \mathrm{SO}_{4} / \mathrm{SO}_{3}$ mixtures is

$$
\mathrm{W}_{1}=\mathrm{k}_{1}[\mathrm{TNT}]
$$

TNT decomposition, where [TNT] is TNT molar concentration.

$$
\mathrm{W}_{2}=\mathrm{k}_{2}\left[\mathrm{TNT} \cdot \boldsymbol{n} \mathrm{H}_{2} \mathrm{SO}_{4}\right],
$$


decomposition of TNT and sulfuric acid complex. The possibility of the formation of such complex follows from the data on solubility of TNT in sulfuric acid [13]. It is quite possible, that, as well as in the case of $\mathrm{NM}$, this complex included the ionized TNT molecule. The relative number of $\mathrm{H}_{2} \mathrm{SO}_{4}$ molecules in the complex $n$ has to be determined from the best correlation of the calculation results with the experimental data.

The considerable influence of "free" $\mathrm{SO}_{3}$ shows, that a reaction with sulfuric anhydride is also essential. One can suppose, that this reaction proceeds between the complex and $\mathrm{SO}_{3}$

$$
\mathrm{W}_{3}=\mathrm{k}_{3}\left[\mathrm{TNT} \cdot n \mathrm{H}_{2} \mathrm{SO}_{4}\right] \cdot\left[\mathrm{SO}_{3}\right]
$$

One can suggest also, that the intermediate stage of transition of the reagents, entering into reaction (9), to its products is the formation of a complex with pyrosulfuric acid $\left(\mathrm{H}_{2} \mathrm{~S}_{2} \mathrm{O}_{7}\right)$ :

$$
\mathrm{TNT} \cdot n \mathrm{H}_{2} \mathrm{SO}_{4}+\mathrm{SO}_{3} \stackrel{\mathrm{k}_{3}}{\longrightarrow} \mathrm{TNT} \cdot(n-1) \mathrm{H}_{2} \mathrm{SO}_{4} \cdot \mathrm{H}_{2} \mathrm{~S}_{2} \mathrm{O}_{7} \stackrel{\mathrm{k}_{4}}{\longrightarrow} \text { products, }
$$

where $\mathrm{k}_{4} \gg \mathrm{k}_{3}\left[\mathrm{SO}_{3}\right]$.

Taking into account the reactions (7-9), the value of $\mathrm{k}_{0}$ in the equation for the quasi first order reaction rate $\left(\mathrm{W}=\mathrm{k}_{0}[\mathrm{TNT}]_{0} \cdot \exp \left(-\mathrm{E}_{\mathrm{a}} / \mathrm{RT}\right)\right)$ can be represented in the form of

$$
\mathrm{k}_{0}=\frac{\mathrm{k}_{01}[\mathrm{TNT}]+\mathrm{k}_{02}\left[\mathrm{TNT} \cdot n \mathrm{H}_{2} \mathrm{SO}_{4}\right]+\mathrm{k}_{03}\left[\mathrm{TNT} \cdot n \mathrm{H}_{2} \mathrm{SO}_{4}\right] \cdot\left[\mathrm{SO}_{3}\right]}{[\mathrm{TNT}]_{0}}
$$

The values of the pre-exponential factors $k_{01}, k_{02}$, and $k_{03}$ for the reactions (7), (8), and (9), as well as the coefficient $n$ have to be defined from the experimental data.

The calculations were carried out at $E_{a}=109 \mathrm{~kJ} / \mathrm{mol}, \gamma=2.027+0.7429 \rho_{0}$ (taken from [5]). Using the obtained ignition delay $\tau_{3}$, the value of $k_{0}$ was calculated as

$$
\mathrm{k}_{0}=\mathrm{C}_{\mathrm{v}} \rho \mathrm{RT}_{3}{ }^{2} /\left(\mathrm{Q}_{\mathrm{V}} \mathrm{M}_{\mathrm{TNT}}[\mathrm{TNT}]_{0} \mathrm{E}_{\mathrm{a}} \tau_{3}\right) \cdot \exp \left(\mathrm{E}_{\mathrm{a}} / \mathrm{RT}_{3}\right)
$$

where $C_{V}$ is the heat capacity of the mixture, $Q_{V}$ is the heat of TNT decomposition. The concentrations $\left(\mathrm{mol} / \mathrm{m}^{3}\right)$ are defined by the relations:

$$
\begin{aligned}
& {[\mathrm{TNT}]_{0}=\left(1-\mathrm{C}_{\mathrm{S}} / 100\right) \cdot \rho / \mathrm{M}_{\mathrm{TNT}}} \\
& {\left[\mathrm{SO}_{3}\right]=\mathrm{S}_{\mathrm{SO} 3} / 100 \cdot \mathrm{C}_{\mathrm{S}} / 100 \cdot \rho / \mathrm{M}_{\mathrm{SO} 3}} \\
& {\left[\mathrm{H}_{2} \mathrm{SO}_{4}\right]=\left(1-\mathrm{S}_{\mathrm{SO}} / 100\right) \cdot \mathrm{C}_{\mathrm{S}} / 100 \cdot \rho / \mathrm{M}_{\mathrm{S}}} \\
& \mathrm{S}_{\mathrm{SO} 3}=\mathrm{M}_{\mathrm{SO} 3} / \mathrm{M}_{\mathrm{H} 20} \cdot(\mathrm{S}-100)
\end{aligned}
$$

where $\mathrm{M}_{\mathrm{SO} 3}, \mathrm{M}_{\mathrm{H2O}}, \mathrm{M}_{\mathrm{TNT}}$, and $\mathrm{M}_{\mathrm{S}}$ are molecular weights of $\mathrm{SO}_{3}$, water, $\mathrm{TNT}$, and sulfuric acid, correspondingly; $\rho$ is the mixture density; $\mathrm{S}_{\mathrm{SO} 3}$ is the mass concentration of "free" $\mathrm{SO}_{3}$ in oleum. The preexponential factor $k_{01}$ corresponds to the decomposition of TNT, remained after interaction with sulfuric acid:

$$
[\mathrm{TNT}]=[\mathrm{TNT}]_{0}-\left[\mathrm{TNT} \cdot n_{2} \mathrm{SO}_{4}\right]
$$

The value of $\mathrm{k}_{02}$ is responsible for $\mathrm{TNT} \cdot n \mathrm{H}_{2} \mathrm{SO}_{4}$ complex decomposition rate, where $n$ molecules of sulfuric acid are needed for one TNT molecule. At TNT surplus the concentration is defined by equality [TNT $\left.\cdot n \mathrm{H}_{2} \mathrm{SO}_{4}\right]=[\mathrm{TNT}]_{0} / n$, at sulfuric acid surplus it is found as [TNT $\left.\cdot n \mathrm{H}_{2} \mathrm{SO}_{4}\right]=[\mathrm{TNT}]_{0}$ (we suppose that the equilibrium is entirely moved to the complex formation). The value of $\mathrm{k}_{03}$ is connected with formation and decomposition under the action of sulfuric anhydride of still more reactive TNT form. The point 
$[\mathrm{TNT}]_{0}=\left[\mathrm{H}_{2} \mathrm{SO}_{4}\right] / n$ corresponds to the transition from quadratic to linear plot. It allows us to determine the $n$ value. It proved to be equal 2 . The values of $\mathrm{k}_{01}, \mathrm{k}_{02}$ and $\mathrm{k}_{03}$ obtained by optimization, are equal to $1.42 \cdot 10^{10} \mathrm{~s}^{-1}, 2.2 \cdot 10^{11} \mathrm{~s}^{-1}$, and $1.2 \cdot 10^{11} 1 \cdot \mathrm{mol}^{-1} \cdot \mathrm{s}^{-1}$, respectively. The values of $\mathrm{k}_{\varnothing}$ calculated using these constants are represented by curves in Fig.8.

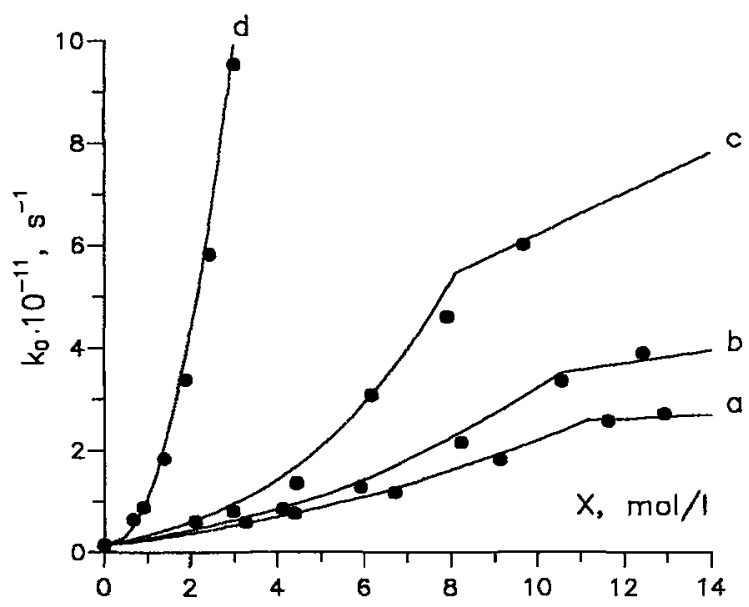

Fig.8. Influence of sulfuric acid $\left(\mathrm{X}=\left[\mathrm{H}_{2} \mathrm{SO}_{4}\right]-\left[\mathrm{SO}_{3}\right]\right.$, mol/l) on decomposition rate of mixtures of TNT and oleum. The points represent the values of $\mathrm{k}_{0}$ calculated on the basis of Dremin theory and the measurements of $d_{f}$; the curves are obtained using the kinetic scheme suggested at $E_{a}=109 \mathrm{~kJ} / \mathrm{mol}, \mathrm{k}_{01}=1.42 \cdot 10^{10} \mathrm{~s}^{-1}$, $\left.\mathrm{k}_{02}=2.20 \cdot 10^{11} \mathrm{~s}^{-1}, \mathrm{k}_{03}=1.20 \cdot 10^{11} 1 \cdot \mathrm{mol}^{-1} \cdot \mathrm{s}^{-1}\right)$. Oleum concentration $(\mathrm{S}, \%)$ : a -100.6 , $\mathrm{b}-101.7, \mathrm{c}-103.8, \mathrm{~d}-108.2$.

In Fig. 4 the points are experimental data, the curves a-d are the results of the calculations carried out using the Eqs. (7-11). Having in mind the model used, they are extended to the region of low acid content. The dashed curve represents the results for mixtures of $N M$ and sulfuric acid $(\mathrm{S}=100.5 \%)$. It is the same curve as the solid line on Fig.1. One can see, that the detonation failure diameter of TNT-based mixtures decreases less abruptly, than for the NM solutions, when acid is added to the system. It can be explained by the ability of nitromethane to form the aci-ion, which being quickly decomposed makes a supplementary contribution to the heat release rate.

\section{CONCLUSIONS}

The results obtained on detonation failure diameter prove a formation in the $\mathrm{NM} / \mathrm{H}_{2} \mathrm{SO}_{4}$ and $\mathrm{TNT} /$ oleum mixtures of the complexes of the nitrocompounds with sulfuric acid having the composition of $\left[\left(\mathrm{CH}_{3} \mathrm{NO}_{2}\right)_{2} \cdot \mathrm{H}_{2} \mathrm{SO}_{4}\right]$ and $\left[\mathrm{TNT} \cdot 2 \mathrm{H}_{2} \mathrm{SO}_{4}\right]$. The decomposition rate of the nitromethonium sulfate is two orders of magnitude greater than that of nitromethane under the conditions considered (P $10 \mathrm{GPa}$, T $1000 \mathrm{~K}$ ). The TNT complex decomposes 15 times faster than the pure TNT. It is said about considerable change of TNT molecule in this complex, may be associated with ionization. This complex reacts with $\mathrm{SO}_{3}$ in oleum. The reaction rate at the maximum concentration of $\mathrm{SO}_{3}\left(\mathrm{C}_{\mathrm{S}}=64 \%, \mathrm{~S}=108.2 \%\right)$ is 4 times higher, than the decomposition rate of the complex, and, hence, 60 times higher, than the decomposition rate of TNT itself. 


\section{REFERENCES}

1. Kondrikov B.N., Kozak G.D., Raykova V.M., Starshinov A.V. DAN SSSR 233 (1977) 402-405.

2. Dremin A.N. DAN SSSR 147 (1962) 870-873.

3. Dremin A.N., Trofimov V.S. PMTF (1964) No 1, 126-131.

4. Enig J.W., Petrone F.J. "The failure diameter theory of Dremin". 5th Symposium (Int.) on Detonation, Pasadena, Ca, Aug. 18-21, 1970, Office of Naval Research, Arlington, Va. ACR-184, pp. 99-104.

5. Gamezo V.N., Kondrikov B.N. "Calculations of the kinetic constants for decomposition of nitromethane and TNT from the data on dependence of failure diameter on initial temperature". Proc. of IV Conference (USSR) on Detonation, Telavi, 1988, vol. 1, pp. 111-117.

6. Gamezo V.N. The heat release kinetics in the reaction zone of detonation wave. Cand. Sci. (Ph.D.) Thesis (Mendeleev University of Chemical Technology, Moscow, 1992).

7. Tarver C.M., Shaw R., Cowperthwaite M. Detonation failure diameter studies of four liquid nitroalkanes. J.Chem.Phys., 64 (1976) 2665-2673.

8. Kondrikov B.N., Raykova V.M. Thermodynamics of combustion and explosion. (Mendeleev University of Chemical Technology, Moscow, 1981).

9. Briger G.I., Romanov Yu.L., Skotnikov V.A., Smimov V.N. J.Fiz.Khim., 54 (1980) 628-632.

10. Makovky A, Lenji L. Chem. Revs. 58 (1958) 627-644.

11. Brand J.C., Horning B.C., Thornley M.B. J.Chem.Soc. (London) (1952) No 4, 1374-1383.

12. Melius C.F. Phil.Trans.R.Soc.(London) A 339 (1992) 365-376.

13. Khoroshev S.M., Kondrikov B.N., Kozak G.D., et al. On the solubility of trinitrotoluene, trinitrobenzene and dinitrotoluene in sulfuric acid. Explosive materials and pyrotechnics. Problems of explosive safety of chemical workshops. (Ed. by B.N.Kondrikov. CNIINTIKPK, Moscow, 1992) 3(218) pp. 14-20. 